\section{Four categories of patient participation in treatment and their linkage to decision-making in a structure of $\mathbf{8 1}$ models}

\author{
Liv-Helen Heggland, ${ }^{1}$ Kjell Hausken ${ }^{2}$ \\ 'Stavanger University Hospital; \\ ${ }^{2}$ Faculty of Social Sciences, \\ University of Stavanger, Norway
}

\begin{abstract}
We clarify patient participation by developing a systematic structure of $3^{4}=81$ models spanned out by three subcategories for each of four categories. Choosing a qualitative descriptive research design, and applying purposive sampling, four doctors, seven nurses, and seven patients were selected to ensure a broad representative sample with experts of varying ages and sexes from medicine and nursing. The preferences of these were mapped onto the theoretical structure. Applying content analysis, meaning units were identified, condensed and coded. The four categories information dissemination, formulation of options, integration of information and control were shown to be exhaustive, and mutually exclusive through time causing a topdown process where one occurs before the other through four stages. The three subcategories specify how patients, healthcare professionals, or both, operate within each category. That is, either patients are active in some sense that is specified, or healthcare professionals are active in some sense, or both are active. Delineating a structure of $3^{4}=81 \bmod$ els, based on four categories and three subcategories, gives a richer structure than what has earlier been available. This almost all-embracing structure enables pinpointing the exact nature of any culture involved in care of patients, which illuminates how the culture reflects or can potentially be altered to reflect values of patient care that we respect.
\end{abstract}

\section{Introduction}

The two purposes of this paper were to develop a theoretical structure of 81 models for assessing patient participation, and to determine attitudes towards patient participation for doctors, nurses, and patients within this structure. Through this structure we intended to fill a gap in the literature by specifying the role of patient participation and how partici- pants partake in decision-making processes in surgical treatment.

We determined empirically that patient participation consists of the four categories information dissemination, formulation of options, integration of information and control. The content of these main concepts is crucial for patient participation. First, patients are concerned about who disseminates information, how much information is disseminated, and how information is disseminated. Second, patients are concerned about which options are available, how these options are conceptualized, and who formulates them. Third, patients are concerned about how information is integrated, e.g. whether its totality constitutes a meaningful whole. Fourth, patients are concerned about who controls and decides what, whether it is interesting to control, and what the consequences are.

Each of these four categories was divided into three subcategories which specify how patients, healthcare professionals, or both, operate within each category. For example, information may flow from healthcare professionals to patients, vice versa, or both ways. This gives a total of $3^{4}=81$ archetypical models which each individual healthcare professional's and patient's preferences are mapped onto. More specifically, we proceeded systematically through a four-dimensional hypercube with three positions along each dimension, which gives $3 \times 3 \times 3 \times 3=81$ positions. These 81 positions were supported with empirical statements by 18 participants.

We showed how four of the 81 models are known from the literature, and showed how they follow from specific choices of subcategories for each category. These four special cases added credibility to the structure of the 81 models. The first is the paternalistic model where patients are passive recipients of care. ${ }^{1}$ The second is the shared model where patients and healthcare professionals exchange information and make decision jointly. ${ }^{2}$ This model strikes a balance between the paternalistic and the third informed model where patients get information from healthcare professionals and make own treatment decisions. ${ }^{3}$ The fourth is the non-paternalistic model which describes, influenced by principal-agent theory, ${ }^{4,5}$ how a principal (the patient) delegates authority to an agent (healthcare professional) to take action. Increasing emphasis on patient participation occurs as we proceed from the first to the fourth model. The other 77 models follow from alternative choices of subcategories for each category. Our research questions are as follows. Which empirical support can be provided for the paternalistic model, the shared model, the informed model, and the non-paternalistic model? In which sense do these four models account for patient participation? Do doctors, nurses, and patients support these
Correspondence: Kjell Hausken, Faculty of Social Sciences, University of Stavanger, 4036 Stavanger, Norway.

Tel.: +4751831632 - Fax: +4751831550

E-mail: kjell.hausken@uis.no

Key words: patient participation, categories, subcategories, surgical treatment, qualitative content analysis.

Acknowledgments: we thank an anonymous referee of this journal for useful comments, and Marianne Storm and Christina Furskog Risa for help with processing the data material.

Contributions: the authors contributed equally.

Conflict of interests: the authors declared no conflicts of interests.

Received for publication: 17 October 2014.

Revision received: 5 January 2015.

Accepted for publication: 5 January 2015.

This work is licensed under a Creative Commons Attribution NonCommercial 3.0 License (CC BYNC 3.0).

(C) Copyright L.-H. Heggland and K. Hausken, 2015 Licensee PAGEPress, Italy

Nursing Reports 2015; 5:4783

doi:10.4081/nursrep.2015.4783

four models differently? How are these four models linked to each other? Do they fully capture patient participation? Can these four models be envisioned as special cases embedded within a broader and more general theoretical structure which captures the breadth and depth of patient participation more thoroughly? Can qualitative descriptive research including purposive sampling be used to enhance our understanding of patient participation? Can empirical statements by doctors, nurses, and patients be used together with content analysis to identify meaning units, codes, and categories which establish a deeper theoretical structure which determines the nature of patient participation?

\section{Background}

Our motivation for providing this theoretical framework was the current state of affairs where the role of patient participation is unclear. Patient participation is an active process that involves patients partaking in decision-making processes. It means enabling individuals to contribute more fully to decisions affecting their own treatment and care. ${ }^{6}$ In practice, patient participation has meant anything from passing on information to full and active participation in partnership with 
professionals. ${ }^{7}$ One attempt of an operational definition was made by Cahill ${ }^{8}$ suggesting that the meaning of patient participation is compared with patient partnership, patient collaboration and involvement ( $\mathrm{p} 561$ ). She proposed three levels. A contract-based association between two parts, healthcare professionals and patients, is at the highest level. Patient participation is at the medium level and involves sharing information and power transfer from healthcare professionals to patients. Patient involvement/collaboration is at the lowest level. The relationship between healthcare professionals and patients has evolved from a traditional paternalistic model where doctors know best and patients are passive recipients, to a partnership where patients act as active participants who are supplied with and supply information and reach a decision alone or jointly with healthcare professionals. ${ }^{9}$ According to Taylor ${ }^{10}$ two key elements in any decision are: i) what is likely to happen; and ii) the value of the outcome to the decision maker. A patient's preference for one outcome or another is a direct reflection of the information available as well as values of the decision maker. Patients should thus be given relevant, accurate information in a form that is amenable to influencing their preferences. Making good decisions in the face of uncertainty requires informing patients about the options and outcomes for each choice, which can be difficult and time consuming. ${ }^{11}$ New political regulations have given patients the right to influence their own treatment in healthcare, which includes the right to participate in choosing between available and medically sound methods of examination and treatment (Norwegian Patients' Rights Act, 1999 p 4; Norwegian National Strategy for Quality Improvement in Health and Social services, 2005). This requires consumer committee meetings to be held regularly across hospitals and within hospitals. At the individual level, however, patient participation and involvement in health services and treatment have not been defined by the authorities and must be developed within each health service institution.

\section{Materials and Methods}

\section{Design, approach and interview guide}

A qualitative descriptive research design was chosen to enable tapping into the breadth and depth of patient participation. The Appendix shows the qualitative interview guide. It was developed with especial attention to patient participation, and used in the qualitative interviews. The guide is influenced by the literature on patient participation, ${ }^{6,8}$ empowerment, ${ }^{12}$ patient participation in decision-making ${ }^{9}$ and active versus passive patient roles. ${ }^{13-15}$ Prior to the data collection, a focus group consisting of three operating room nurses and one surgeon was created to contribute in the guide validation. They discussed their perceptions of and opinions towards the questions in the interview guide, which enabled the authors to clarify the content and wording of the questions. The guide has one section for healthcare professionals and patients, one section for healthcare professionals only, and one section for patients only. Each question in the guide was read verbatim to each participant, with follow-up questions, clarifications and prompts.

\section{Ethics}

The Norwegian Ethical Committee (Ref. No.: 3.2007.1984), the Norwegian Social Science Data Services (no. 17468), and the head of Stavanger University Hospital, Norway approved the study. The participants were invited to participate, the study was thoroughly explained to them, and they were guaranteed full confidentiality. Before obtaining consent, they were told that participation was voluntary and that they could withdraw at any time according to The World Medical Association Declaration of Helsinki in 2000.

\section{Participants}

The interviews were conducted by one of the authors, Dr. Liv-Helen Heggland, at Stavanger University Hospital, Norway, which has 700 beds, 7000 employees, serves a population of 300,000 , has a budget of 4,7 billion NOK in 2014 , covers an area of 200,000 square meters, is involved in research, provides most medical services for most patients, and is in partnership with MD Anderson Cancer Center in Houston. Applying purposive sampling, ${ }^{16-18}$ the four doctors, seven nurses, and seven patients were selected to ensure a broad representative sample with experts of varying ages and sexes from medicine and nursing. Three groups of participants were interviewed to ensure diverse and potentially contradictory viewpoints to potentially span the domains of the theoretical structure. Tables 1 and 2 contain the participants' characteristics (all Caucasian with Norwegian citizenship) and model preferences. The head-managers in six surgical wards selected the participants using the following inclusion and exclusion criteria for each group of the participants. Each head manager supervises $30-80$ healthcare professionals and knows these reasonably well, but does not know the patients well since these are present 1-2 days for surgery. Qualitative interviews are time consuming and it was determined that 18 interviews are suitable for analysis. It was also determined that an equal number of nurses and patients is suitable for interviewing. The hospital has three times as many nurses as doctors. It was possible for the head manager to obtain four doctors for interviewing. We think that the authors' choice of purposive sampling conveyed to the head-managers, combined with the head-managers' choice of the 18 participants, is justified as a scientifically good sampling method. Two weeks were designated for interviewing which took place between 10 a.m. and 2 p.m. This time constraint gave an upper limit for the number of participants that could be interviewed. It was determined to interview an equal number of nurses and patients, and fewer doctors. Eleven healthcare professionals were invited among those that were at work at the day of the interview and available for interviewing, and all accepted. Nine patients were invited based on who undertook surgery at the day of the interview and were available for interviewing. Two of the invited patients, above 65 years, declined due to feeling not ready to be interviewed. Seven of the patients accepted to be interviewed. All 18 participants found the interviews interesting and did not perceive participation as coercion. Both healthcare professionals and patients should be above 25 years, to ensure maturity, and they should speak and understand Norwegian well. Very few patients are below 25 years and the age requirement did not influence the selection. All seven patients are 49-65 years were the availability is highest. All seven nurses are female since few male nurses work at the hospital and none were available at the designated interviewing times. All the patients had a consultation with a doctor ranging from a few weeks to several months prior to their surgery. They had a new consultation with the doctor the day before surgery. The data were collected from in-depth interviews each lasting 45-90 min (average one hour). The 18 participants were interviewed one-on-one in a room with closed door, the patients in their patient room and the healthcare professionals in an office. Lighting was good and no disturbances occurred. All interviews were audio taped with the permission of the respondents and transcribed. One patient, p3, with no earlier operations, was interviewed two days before the operation (These two patients were moved from the orthopedic ward to rehabilitation at another institution after surgery and could not be tracked thereafter because of anonymity.). The six remaining patients, all with earlier operations, were interviewed 2-7 days after the operation. After the first five to six interviews with patients it became obvious that similarly characterized answers were delivered, with no new information. Applying qualitative interview criteria, it was thus concluded that interviews with seven patients were sufficient to achieve saturation. 


\section{Units of analysis}

We operate with three units of analysis. First and foremost, the main unit of analysis is each individual participant, for whom we present empirical statements and preferences. Second, we compare and contrast the various subgroups as units of analysis, i.e. doctors, nurses, and male and female patients. Third, we characterize attitudes toward patient participation for the whole group of 18 participants, as a unit of analysis.

\section{Data analysis and conceptual development}

Qualitative content analysis was used as suggested by Graneheim and Lundman. ${ }^{19}$ Content analysis is usually conducted in three manners.
The first manner used in this paper applied Graneheim and Lundman's ${ }^{19}$ methodological logic. Tables 3 and 4 and Figure 1 indicated the summarized results of the manifest and latent qualitative content analysis. The manifest content analysis pertained to what both the healthcare professionals and the patients expressed; whereas, the latent content analysis pertained to the meaning of what they stated. Examples of related research are Granerud and Severinsson, ${ }^{20}$ Høye and Severinsson, ${ }^{21}$ Nystedt et al..$^{22}$ The second manner analyzes manifest content, exemplified by Hök et al. ${ }^{23}$ They identified, coded and sorted into categories without meaning analysis. The third manner analyzes latent content, exemplified by Gustafsson et al..$^{24}$ They explored older people's body experiences, developing meaning units, condensed meaning units, and themes, without explicit categorization. Graneheim and Lundman ${ }^{19}$ clarified the three manners. Applying Morse, ${ }^{25}$ a category is defined as a collection of similar data sorted into the same place, which identifies and describes the characteristics of the category. This enables the category to be defined, and then compared and contrasted with other categories ( $\mathrm{p}$ 727). Furthermore, Morse ${ }^{25}$ defined a theme as a meaningful 'essence' that runs through the data (p 727). Our content analysis proceeded through the following seven points (Tables 3 and 4; Figure 1). The analysis resembled the methodological logic suggested by Graneheim and Lundman ${ }^{19}$ as follows: i) the interviews were read repeatedly by the authors to ensure a

Table 1. Participants characteristics and model preferences.

\begin{tabular}{|c|c|c|c|c|c|c|c|}
\hline Profession & $\begin{array}{l}\text { Ward/ } \\
\text { surgery }\end{array}$ & $\begin{array}{l}\text { Earlier } \\
\text { surgery }\end{array}$ & Sex & Age & $\begin{array}{l}\text { Education/ } \\
\text { profession }\end{array}$ & $\begin{array}{l}\text { Specific model } \\
\text { preference* }\end{array}$ & $\begin{array}{l}\text { General model } \\
\text { preference }\end{array}$ \\
\hline Doctor dl & Internship & - & $\mathrm{F}$ & 28 & MD & A2 (alt A3), B2, C1, D1 (alt D3) & Informed (alt shared) \\
\hline Doctor d2 & Internship & - & M & 28 & MD & A2 (alt A3), B2, C1, D1 (alt D3) & Informed (alt shared) \\
\hline Doctor d3 & Blood vessels/thorax & - & M & 40 & MD+specialization & A3, B3, C3, D3 & Shared \\
\hline Doctor d4 & Orthopedic & - & M & 59 & MD+specialization & $\mathrm{A} 2, \mathrm{~B} 2, \mathrm{Cl}, \mathrm{D} 1$ & Informed \\
\hline Nurse $\mathrm{nl}$ & Urologic & - & $\mathrm{F}$ & 27 & $\mathrm{BSc}$ & A3, B3, C3, D3 & Shared \\
\hline Nurse n2 & Gastrological & - & $\mathrm{F}$ & 26 & $\mathrm{BSc}$ & A3, B3, C3, D3 & Shared \\
\hline Nurse n3 & Central-surgery unit & - & F & 43 & $\mathrm{BSc}$ & A2 (alt A3), B2 (alt B3), C2 (alt C3), D2 & Paternalistic (alt shared) \\
\hline Nurse n4 & Central-surgery unit & - & $\mathrm{F}$ & 51 & $\mathrm{BSc}$ & A2 (alt A3), B2 (alt B3), C2 (alt C3), D2 & Paternalistic (alt shared) \\
\hline Nurse n5 & Day-surgery unit & - & $\mathrm{F}$ & 54 & BSc+specialization & A2 (alt A3), B2 (alt B3), C2 (alt C3), D2 & Paternalistic (alt shared) \\
\hline Nurse n6 & Orthopedic & - & $\mathrm{F}$ & 58 & $\mathrm{BSc}$ & A3, B3, C3, D3 & Shared \\
\hline Nurse n7 & Day-surgery unit & - & $\mathrm{F}$ & 62 & BSc+specialization & A2 (alt A3), B2 (alt B3), C2 (alt C3), D2 & Paternalistic (alt shared) \\
\hline Patient pl & Back operation & $\begin{array}{c}\text { Yes, } \\
\text { several back } \\
\text { operations }\end{array}$ & $\mathrm{F}$ & 51 & BSc nursing & A2, B2, C1, D1 & Informed \\
\hline Patient p2 & $\begin{array}{l}\text { Ventricle-bowel } \\
\text { operation }\end{array}$ & $\begin{array}{l}\text { Yes, two on } \\
\text { same issue }\end{array}$ & $\mathrm{F}$ & 60 & Unknown, housewife & A3, B3, C3, D3 (alt D1) & Shared (alt informed) \\
\hline Patient p3 & Hip replacement & No & $\mathrm{F}$ & 63 & Unknown, housewife & A2 (alt A3), B2 (alt B3), C2 (alt C3), D2 & Paternalistic (alt shared) \\
\hline Patient p4 & Ovaries-hysterectomy & $\begin{array}{c}\text { Mastectomy } \\
\text { cancer mamma }\end{array}$ & $\mathrm{F}$ & 65 & MSc in teaching & A3, B3, C3, D3 (alt D1) & Shared (alt informed) \\
\hline Patient p5 & $\begin{array}{c}\text { Kidney } \\
\text { transplantation }\end{array}$ & $\begin{array}{c}\text { Yes, kidney } \\
\text { transplantation }\end{array}$ & M & 49 & Bookkeeper & A2, B2, C2, D2 & Paternalistic \\
\hline Patient p6 & $\begin{array}{l}\text { Gastrectomy } \\
\text { cancer } \\
\text { ventriculi }\end{array}$ & $\begin{array}{l}\text { Arm surgery } \\
\text { when young }\end{array}$ & M & 61 & Engineer & A2, B2, C2, D2 & Paternalistic \\
\hline Patient p7 & $\begin{array}{l}\text { Urological } \\
\text { operation }\end{array}$ & $\begin{array}{c}\text { Yes, kidney } \\
\text { stone operation }\end{array}$ & M & 62 & MSc engineering & A3, B3, C3, D3 (alt D1) & Shared (alt informed) \\
\hline
\end{tabular}

*The 12 specific model preferences A1,A2,A3,B1,B2,B3,Cl,C2,C3,D1,D2,D3 are explained in Table 4.

Table 2. Model preferences across participants.

\begin{tabular}{|c|c|c|c|c|c|c|c|}
\hline Model & $\begin{array}{c}4 \\
\text { doctors }\end{array}$ & $\begin{array}{c}7 \\
\text { nurses }\end{array}$ & $\begin{array}{c}\text { All } 11 \text { healthcare } \\
\text { professionals }\end{array}$ & $\begin{array}{l}4 \text { female } \\
\text { patients }\end{array}$ & $\begin{array}{l}3 \text { male } \\
\text { patients }\end{array}$ & $\begin{array}{c}\text { All } 7 \\
\text { patients }\end{array}$ & $\begin{array}{c}\text { All } 18 \\
\text { participants }\end{array}$ \\
\hline Paternalistic & 0 & 4 & 4 & 1 & 2 & 3 & 7 \\
\hline Shared & 1 & 3 & 4 & 2 & 1 & 3 & 7 \\
\hline Informed & 3 & 0 & 3 & 1 & 0 & 1 & 4 \\
\hline Non-paternalistic & 0 & 0 & 0 & 0 & 0 & 0 & 0 \\
\hline
\end{tabular}



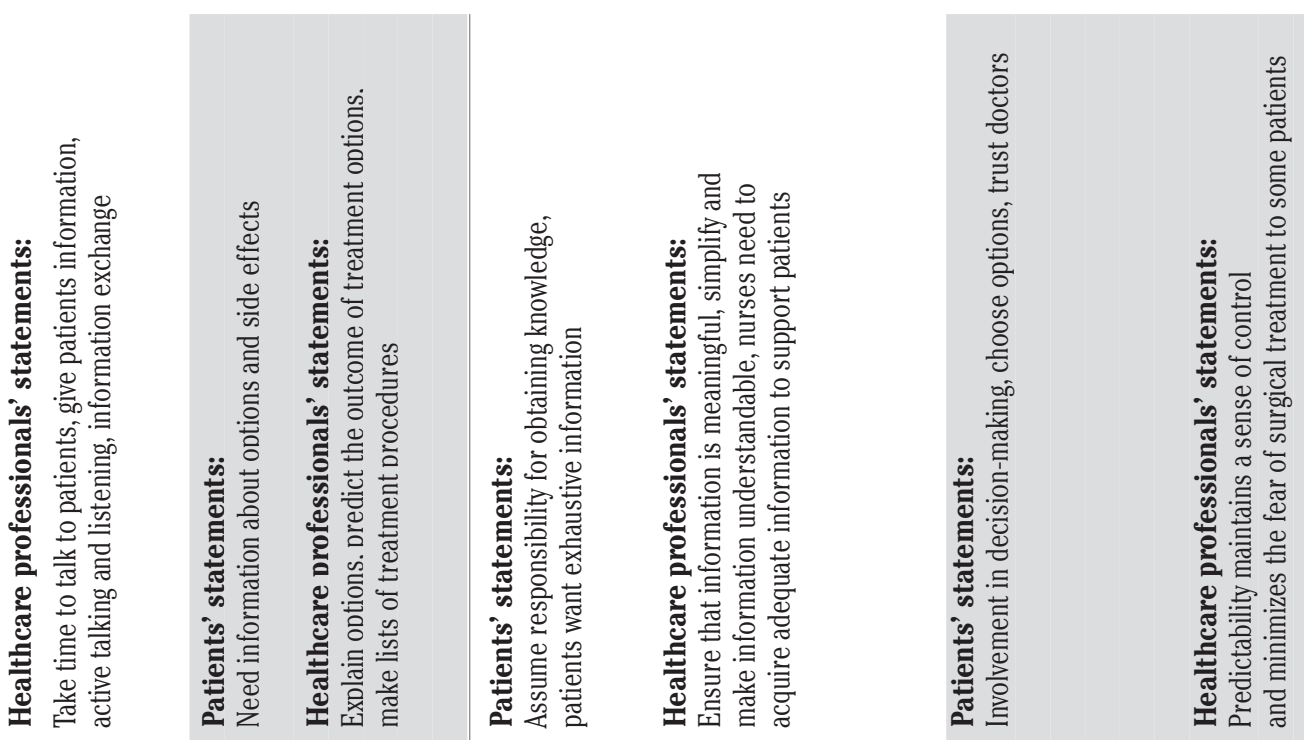

莣㝒总

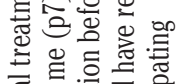

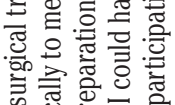

की 胥芯芯

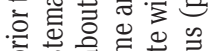

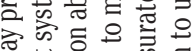

क्षे w.

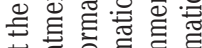

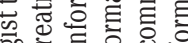

응 정 후응

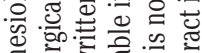

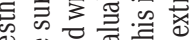

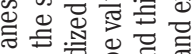

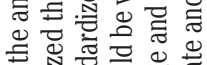

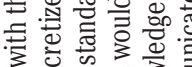

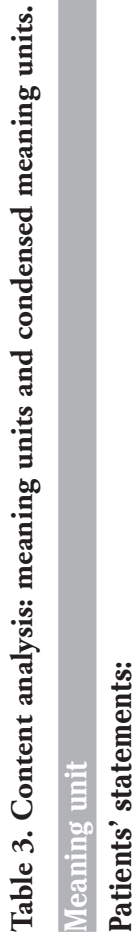

on of o

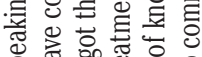

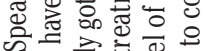

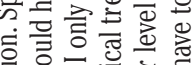

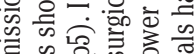

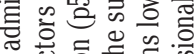

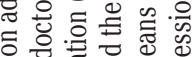

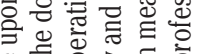

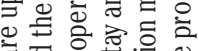

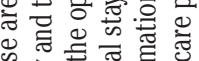

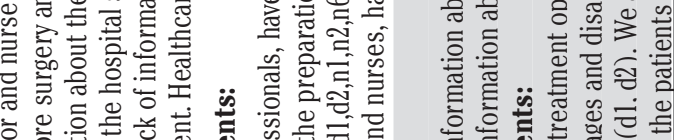

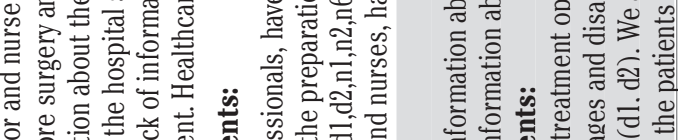

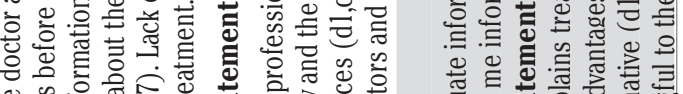

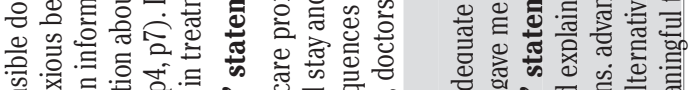

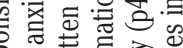

क

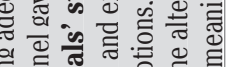

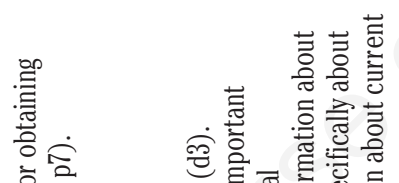

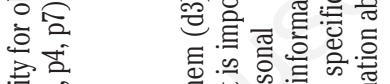

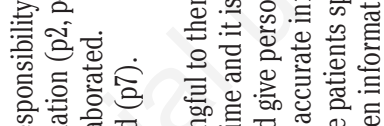

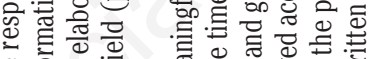

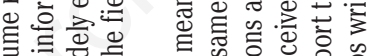

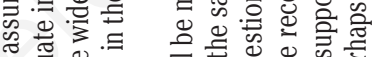

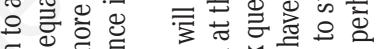

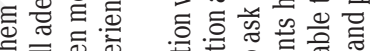

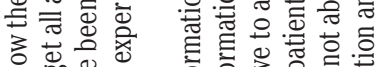

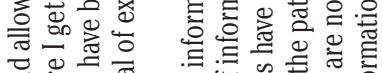

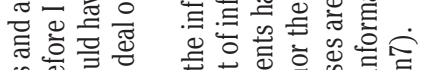

品 훙ㅎㅀ

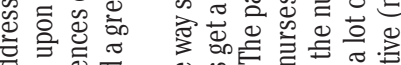

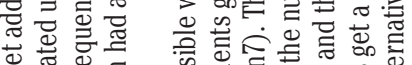

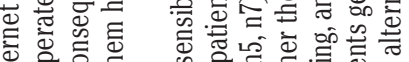

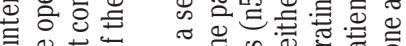

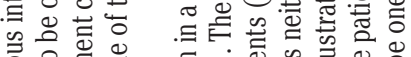

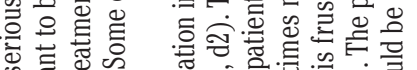

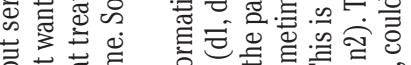

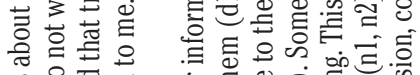

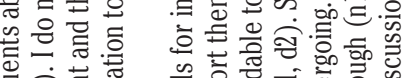

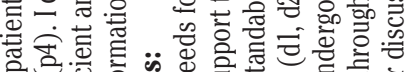

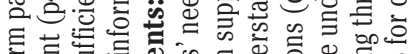

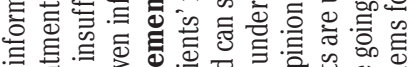

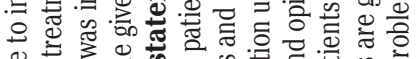

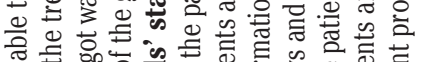

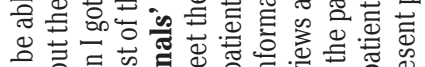

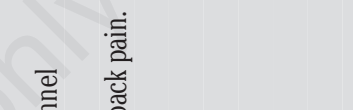

兽

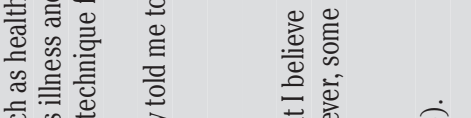

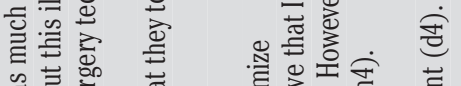

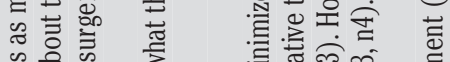

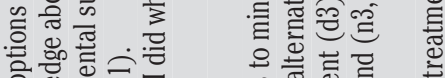

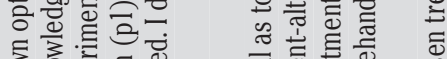

o

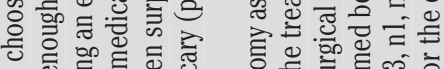

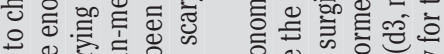

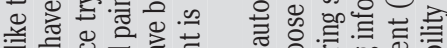

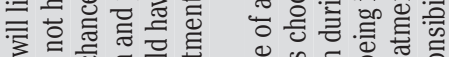

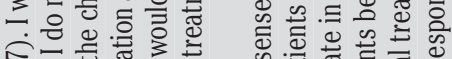

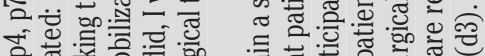

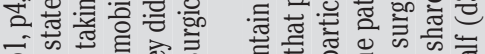

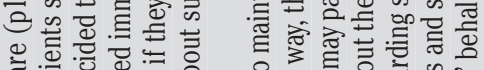

ฮั

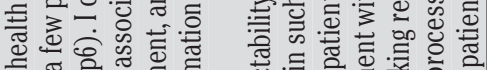

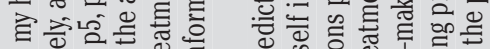

원

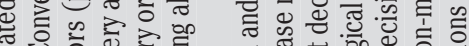

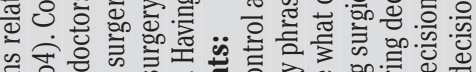

क古它 क人

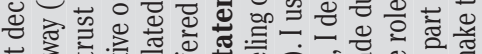

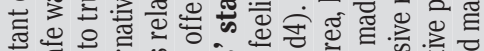

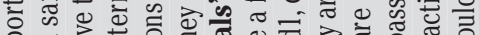

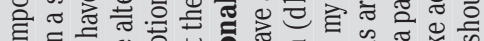

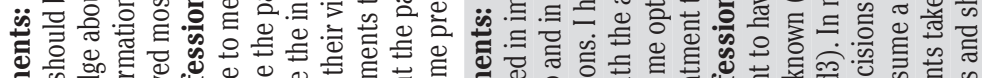

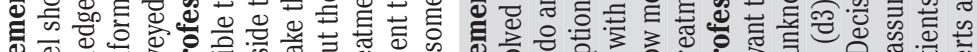

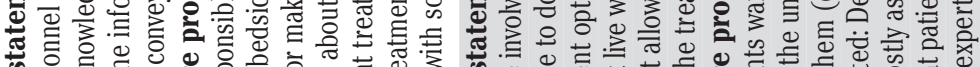

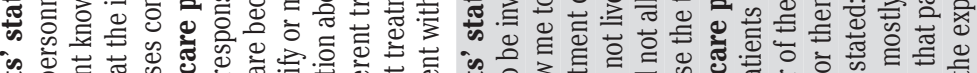

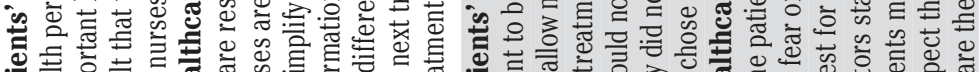

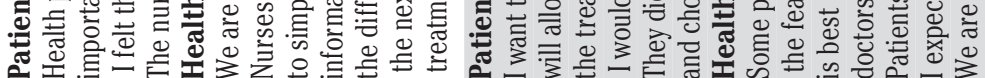




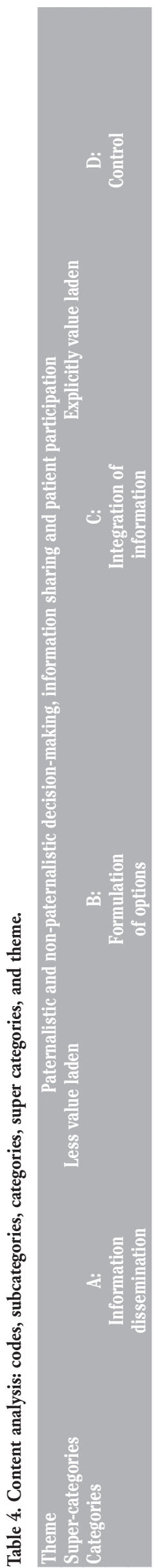

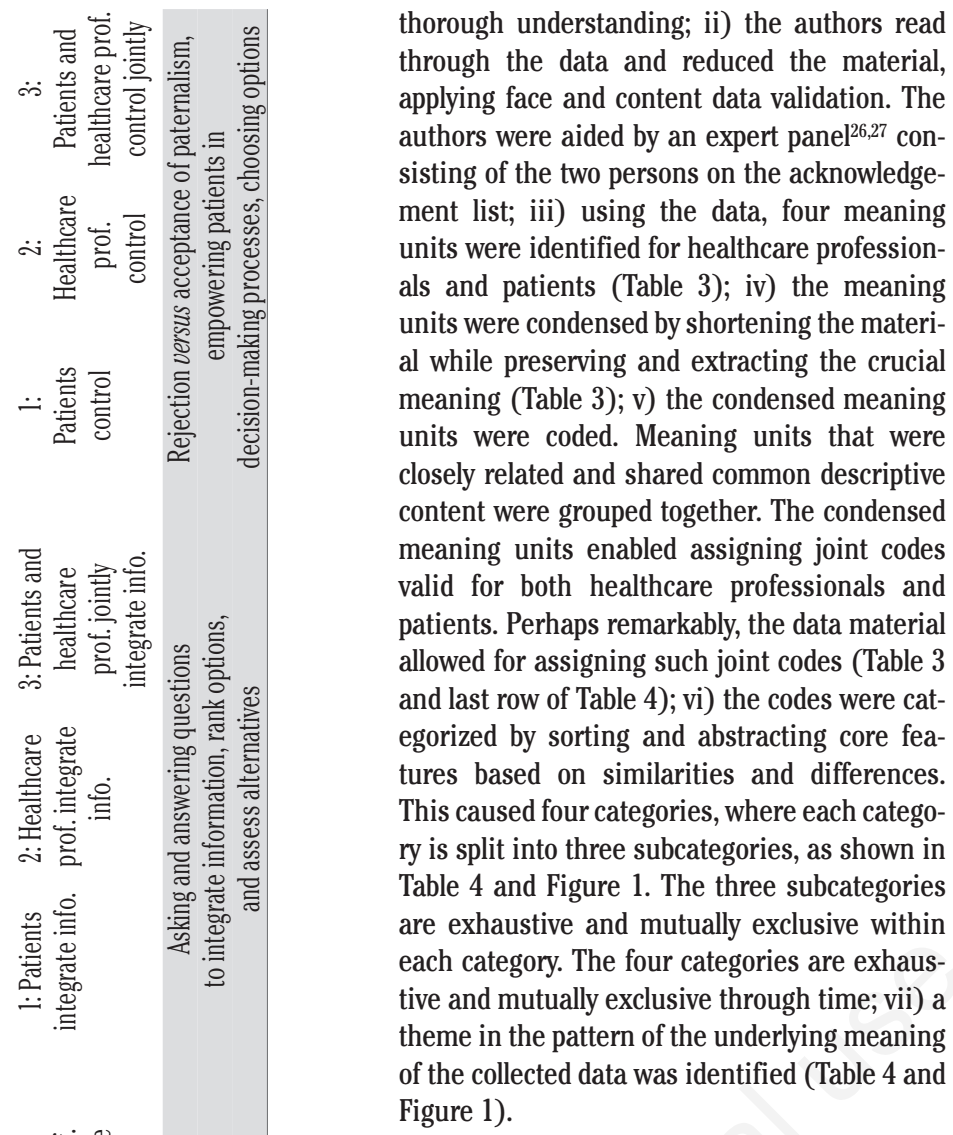

The methodological rigor, including credibility and dependability, for the data analyses were ensured by proceeding carefully through these seven points, verifying that each point has been thoroughly addressed before continuing to the next point, i.e. absorbing the 18 interviews, conferring with the expert panel, using the data to establish meaning units, condensing the meaning units, coding, developing categories and subcategories, and identifying a theme.

\section{Results}

The empirical statements by the three groups of participants are in Table 3 shown in the left column. The statements were formulated as representative and illustrative responses by each participant to the questions in the interview guide applying the 7-point methodological logic in the previous section. The statements were grouped in two manners using the methodological logic in the previous section. First they were grouped into Patients' statements where $\mathrm{p} 1, \ldots, \mathrm{p} 7$ refer to the seven patients in Table 1, and Healthcare professionals' statements where $n 1, \ldots, n 7$ refers to the seven nurses and $\mathrm{d} 1, \ldots, \mathrm{d} 4$ refer to the four doctors. Second, applying content analysis, four meaning units were identified, condensed and coded. That is, based on the condensed meaning unit shown in Table 3 in the right col-

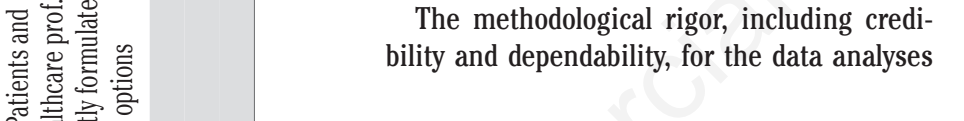

Theme

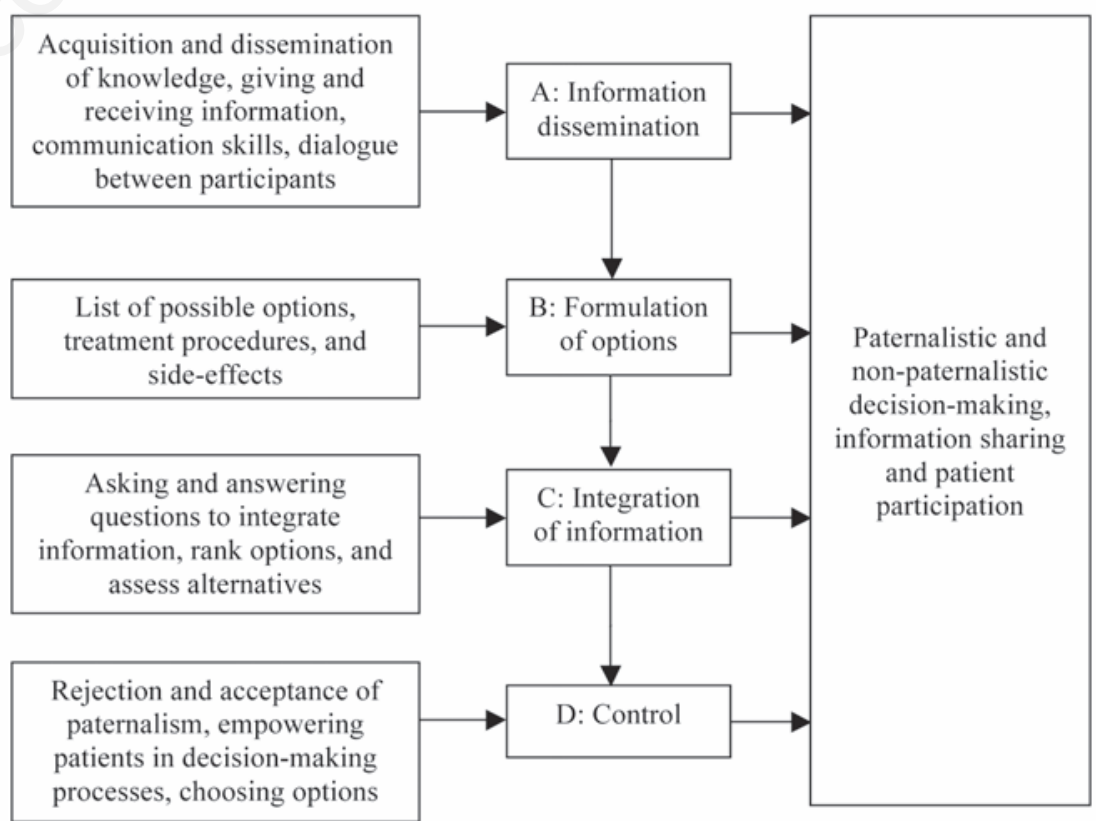

Figure 1. Content analysis: codes, categories and theme. 
umn (in four groups from top to bottom), and the codes shown in the bottom row in Table 4 (in four groups from left to right), the empirical statements were grouped to fit into each of these four codes. Sorting and abstracting core features of the four codes based on similarities and differences caused the four categories and three subcategories for each category. That is, the four codes in the bottom row in Table 4 caused the $3 \times 4=12$ subcategories in the second lowest row (i.e. three subcategories for each category) and the four categories in the third lowest row. The transition from codes to categories is also shown in Figure 1.

The four categories information dissemination, formulation of options, integration of information and control, labeled A,B,C,D, respectively, are mutually exclusive through time. Furthermore, category A occurs in time before category $B$ which occurs before category C which occurs before category D. We refer to this four-stage process as top down where category A (first stage) is at the top (occurs first) and category D (fourth stage) is at the bottom (occurs last). This top down approach has been illustrated with the downward arrows in Figure 1 and is descriptive of patient participation. That is, first, information dissemination occurred. Second, options were formulated; third, information would be integrated; and fourth and finally, controls would occur.

The three subcategories for each category in Table 4 are mutually exclusive. They specify how patients, healthcare professionals, or both, operate within each category. Information dissemination can go from patient to healthcare professionals, the other way, or both ways. That is, the subcategories specify whether information flows one or both ways between healthcare professionals and patients, and whether healthcare professionals or patients or both formulate options, integrate information, and take control through decision-making. Summing up so far, the empirical statements by the 18 participants in Table 3 were condensed, coded, and caused four categories with associated subcategories in a top down process through four stages (one stage for each category), see Figure 1.

The top down process through the four categories allowed for designing a total of $3^{4}=81$ archetypical models dependent on which of the three subcategories is chosen at each of the four stages in the process. Our conceptual apparatus allows for a comprehensive investigation of how patient participation is organized in healthcare through these subcategories. Applying combinatorial mathematics, each of the 81 models thus consists of a specification $\mathrm{Ah}, \mathrm{Bi}, \mathrm{Cj}, \mathrm{Dk}$, where $\mathrm{h}, \mathrm{i}, \mathrm{j}, \mathrm{k}=1,2,3$, spanning out the four-dimensional hypercube with three positions along each dimension. The 81 models are written out in Table 5 , from $\mathrm{A} 1, \mathrm{~B} 1, \mathrm{C} 1, \mathrm{D} 1$ to $\mathrm{A} 3, \mathrm{~B} 3, \mathrm{C} 3, \mathrm{D} 3$.
Table 5. Constructing the 81 models from the four categories A,B,C,D, where each category has three subcategories $1,2,3$.

\begin{tabular}{|c|c|c|c|c|}
\hline $\begin{array}{l}\text { Categories } \\
\text { Subcategories }\end{array}$ & $\begin{array}{c}\text { A } \\
123\end{array}$ & $\begin{array}{c}\text { B } \\
123\end{array}$ & $\begin{array}{c}C \\
123\end{array}$ & $\begin{array}{c}\text { D } \\
123\end{array}$ \\
\hline Model 1 & $\mathrm{Al}$ & B1 & $\mathrm{Cl}$ & D1 \\
\hline Model 2 & $\mathrm{Al}$ & B1 & $\mathrm{Cl}$ & D2 \\
\hline Model 3 & $\mathrm{Al}$ & B1 & $\mathrm{Cl}$ & D3 \\
\hline Model 4 & $\mathrm{Al}$ & B1 & $\mathrm{C} 2$ & D1 \\
\hline Model 5 & $\mathrm{Al}$ & B1 & $\mathrm{C} 2$ & D2 \\
\hline Model 6 & $\mathrm{Al}$ & B1 & $\mathrm{C} 2$ & D3 \\
\hline Model 7 & $\mathrm{Al}$ & B1 & C3 & D1 \\
\hline Model 8 & $\mathrm{Al}$ & B1 & C3 & D2 \\
\hline Model 9 & $\mathrm{Al}$ & B1 & $\mathrm{C} 3$ & D3 \\
\hline Model 10 & $\mathrm{Al}$ & B2 & $\mathrm{Cl}$ & D1 \\
\hline Model 11 & $\mathrm{Al}$ & B2 & $\mathrm{Cl}$ & D2 \\
\hline Model 12 & $\mathrm{Al}$ & B2 & $\mathrm{Cl}$ & D3 \\
\hline Model 13 & $\mathrm{Al}$ & B2 & $\mathrm{C} 2$ & D1 \\
\hline Model 14 & $\mathrm{Al}$ & B2 & $\mathrm{C} 2$ & D2 \\
\hline Model 15 & $\mathrm{Al}$ & B2 & $\mathrm{C} 2$ & D3 \\
\hline Model 16 & $\mathrm{Al}$ & B2 & C3 & D1 \\
\hline Model 17 & $\mathrm{Al}$ & B2 & C3 & D2 \\
\hline Model 18 & $\mathrm{Al}$ & B2 & C3 & D3 \\
\hline Model 19 & $\mathrm{Al}$ & B3 & $\mathrm{Cl}$ & D1 \\
\hline Model 20 & $\mathrm{Al}$ & B3 & $\mathrm{Cl}$ & D2 \\
\hline Model 21 & $\mathrm{Al}$ & B3 & $\mathrm{Cl}$ & D3 \\
\hline Model 22 & $\mathrm{Al}$ & B3 & $\mathrm{C} 2$ & D1 \\
\hline Model 23 & $\mathrm{Al}$ & B3 & $\mathrm{C} 2$ & D2 \\
\hline Model 24 & $\mathrm{Al}$ & B3 & $\mathrm{C} 2$ & D3 \\
\hline Model 25 & $\mathrm{Al}$ & B3 & $\mathrm{C} 3$ & D1 \\
\hline Model 26 & $\mathrm{Al}$ & B3 & C3 & D2 \\
\hline Model 27 & $\mathrm{Al}$ & B3 & C3 & D3 \\
\hline Model 28 & A2 & B1 & $\mathrm{Cl}$ & D1 \\
\hline Model 29 & A2 & B1 & $\mathrm{Cl}$ & D2 \\
\hline Model 30 & $\mathrm{~A} 2$ & B1 & $\mathrm{Cl}$ & D3 \\
\hline Model 31 & A2 & B1 & $\mathrm{C} 2$ & D1 \\
\hline Model 32 & $\mathrm{~A} 2$ & B1 & $\mathrm{C} 2$ & D2 \\
\hline Model 33 & $\mathrm{~A} 2$ & B1 & $\mathrm{C} 2$ & D3 \\
\hline Model 34 & $\mathrm{~A} 2$ & B1 & $\mathrm{C} 3$ & D1 \\
\hline Model 35 & $\mathrm{~A} 2$ & B1 & C3 & D2 \\
\hline Model 36 & A2 & B1 & C3 & D3 \\
\hline Model 37 & A2 & B2 & $\mathrm{Cl}$ & D1 \\
\hline Model 38 & $\mathrm{~A} 2$ & B2 & $\mathrm{Cl}$ & D2 \\
\hline Model 39 & $\mathrm{~A} 2$ & B2 & $\mathrm{Cl}$ & D3 \\
\hline Model 40 & $\mathrm{~A} 2$ & B2 & $\mathrm{C} 2$ & D1 \\
\hline Model 41 & $\mathrm{~A} 2$ & B2 & $\mathrm{C} 2$ & D2 \\
\hline Model 42 & A2 & B2 & $\mathrm{C} 2$ & D3 \\
\hline Model 43 & $\mathrm{~A} 2$ & B2 & $\mathrm{C} 3$ & D1 \\
\hline Model 44 & $\mathrm{~A} 2$ & B2 & C3 & D2 \\
\hline Model 45 & $\mathrm{~A} 2$ & B2 & $\mathrm{C} 3$ & D3 \\
\hline Model 46 & $\mathrm{~A} 2$ & B3 & $\mathrm{Cl}$ & D1 \\
\hline Model 47 & $\mathrm{~A} 2$ & B3 & $\mathrm{Cl}$ & D2 \\
\hline Model 48 & A2 & B3 & $\mathrm{Cl}$ & D3 \\
\hline Model 49 & $\mathrm{~A} 2$ & B3 & $\mathrm{C} 2$ & D1 \\
\hline Model 50 & $\mathrm{~A} 2$ & B3 & $\mathrm{C} 2$ & D2 \\
\hline
\end{tabular}


Table 5. Continued from previous page.

\begin{tabular}{|c|c|c|c|c|}
\hline $\begin{array}{l}\text { Categories } \\
\text { Subcategories }\end{array}$ & $\begin{array}{c}\text { A } \\
123\end{array}$ & $\begin{array}{c}\text { B } \\
123\end{array}$ & $\begin{array}{c}C \\
123\end{array}$ & $\begin{array}{c}\text { D } \\
123\end{array}$ \\
\hline Model 51 & $\mathrm{~A} 2$ & B3 & $\mathrm{C} 2$ & D3 \\
\hline Model 52 & A2 & B3 & C3 & D1 \\
\hline Model 53 & A2 & B3 & C3 & D2 \\
\hline Model 54 & A2 & B3 & C3 & D3 \\
\hline Model 55 & A3 & B1 & $\mathrm{Cl}$ & D1 \\
\hline Model 56 & A3 & B1 & $\mathrm{Cl}$ & D2 \\
\hline Model 57 & A3 & B1 & $\mathrm{Cl}$ & D3 \\
\hline Model 58 & A3 & B1 & C2 & D1 \\
\hline Model 59 & A3 & B1 & C2 & D2 \\
\hline Model 60 & A3 & B1 & C2 & D3 \\
\hline Model 61 & A3 & B1 & C3 & D1 \\
\hline Model 62 & A3 & B1 & $\mathrm{C} 3$ & D2 \\
\hline Model 63 & A3 & $\mathrm{B} 1$ & C3 & D3 \\
\hline Model 64 & A3 & B2 & $\mathrm{Cl}$ & D1 \\
\hline Model 65 & A3 & B2 & $\mathrm{Cl}$ & D2 \\
\hline Model 66 & A3 & B2 & $\mathrm{Cl}$ & D3 \\
\hline Model 67 & A3 & B2 & $\mathrm{C} 2$ & D1 \\
\hline Model 68 & A3 & B2 & C2 & D2 \\
\hline Model 69 & A3 & B2 & $\mathrm{C} 2$ & D3 \\
\hline Model 70 & A3 & B2 & C3 & D1 \\
\hline Model 71 & A3 & B2 & C3 & D2 \\
\hline Model 72 & A3 & B2 & C3 & D3 \\
\hline Model 73 & A3 & B3 & $\mathrm{Cl}$ & D1 \\
\hline Model 74 & A3 & B3 & $\mathrm{Cl}$ & D2 \\
\hline Model 75 & A3 & B3 & $\mathrm{Cl}$ & D3 \\
\hline Model 76 & A3 & B3 & $\mathrm{C} 2$ & D1 \\
\hline Model 77 & A3 & B3 & $\mathrm{C} 2$ & D2 \\
\hline Model 78 & A3 & B3 & C2 & D3 \\
\hline Model 79 & A3 & B3 & C3 & D1 \\
\hline Model 80 & A3 & B3 & C3 & D2 \\
\hline Model 81 & A3 & B3 & C3 & D3 \\
\hline
\end{tabular}

\section{The relevance of the four}

categories and subcategories, and their linkage to patient

\section{participation in four models}

The top down process implied 81 models of healthcare organization, dependent on which subcategory is chosen at each of the four stages, i.e. for each of the four categories. The structure of the 81 models is evidence-based, emerging from interviewing four doctors, seven nurses, and seven patients. But, the structure of the $3^{4}=81$ models is also theoretical. The general theme identified in the pattern of the underlying meaning of the collected data is paternalistic and non-paternalistic decision-making, information sharing and patient participation. This theme is shown in Table 4 and Figure 1 and allows illustrating the 81 models more thoroughly. That is, support for the structure of the 81 models developed in this paper is provided by the fact that four of the 81 models are the literature-based models known as the paternalistic model [A2 (alt. A3), B2, C2, D2], the shared model (A3, B3, C3,
D3), the informed model (A2, B2, C1, D1), and the non-paternalistic model [A1 (alt. A3), B1, $\mathrm{C} 1, \mathrm{D} 1]$, with gradually increasing emphasis on patient participation. That is, the emphasis on patient participation increases as we move from the paternalistic to the non-paternalistic model.

- Paternalistic model: patients are passive recipients of care. ${ }^{1}$

- Shared model: strikes a balance between the paternalistic model and the informed model. ${ }^{12,28}$

- Informed model: patients get information and make own treatment decisions. ${ }^{3}$

- Non-paternalistic model: a principal (the patient) delegates authority to an agent (healthcare professional) to take action., ${ }^{4,5}$

We now proceed to explain precisely how these four models are special cases of our conceptual apparatus of 81 models, which implicitly illustrates how the 77 other models can be designed. The paper allows for a comprehensive investigation of how patient participation is organized in healthcare through these 81 models. As we illustrate these four of the 81 models, we use the letters A,B,C,D to express the four categories and the numbers $1,2,3$ to express the subcategories (Tables 4 and 5). We also provide statements by the participants to buttress additional empirical support for the four models.

\section{Paternalistic model: A2 (alt.A3), B2, C2, D2}

For information dissemination two views exist for this model. The main view (A2) is that information flows from healthcare professionals to patients who provide informed consent to recommended treatments. ${ }^{3}$ Doctor $\mathrm{d} 3$ said:

There is a subjective opinion included in my information to the patients.

The alternative view (A3) is that information also can flow the other way. The patient gives information about symptoms and problems and expects the doctor to make a reliable diagnosis. Patient p5 stated:

$I$ received the information prior to surgery and treatment from the doctors. I have never been given written information and not much information about what could happen after discharge.

The kinds of information flowing the two ways are often different in this model. After information dissemination, healthcare professionals formulate options (B2), integrate information (C2), and take control (D2). The healthcare view is that illness can only be effectively diagnosed and treated by expert professionals assessed by doctor $\mathrm{d} 3$ who stated that the doctors present the options that are the best for the patients. Patient $\mathrm{p} 6$ said that the doctors did not ask him about his opinion:

I did as I was told and accepted the treatment they told me I needed. The doctors knew what they are doing. I trust that they know what they do $100 \%$.

Four of the nurses, n3,n4,n5,n7, stated that patients mostly assume a passive role during decision-making regarding surgical treatment and that the patients trust healthcare professionals to do what is best for them. Furthermore, the doctors recommend the options that are the best for the patients.

These results in the data are consistent with literature findings. Parsons ${ }^{1}$ stated that patients are regarded as helpless and dependent, and that decisions regarding patients' care are within the domain of their doctor. Kennedy ${ }^{29}$ stated that healthcare professionals are considered to know what is in patients' best interest underpinned by professional codes of ethics. Patients expecting a benefit sometimes encounter healthcare personnel which they perceive as paternalistic. One example is young women with hemorrhagic problems preferring hysterectomy. Entwistle $e t$ $a l .{ }^{30}$ illustrated how some of these women have found it difficult to persuade their general 
practitioner to refer them to a specialist or to persuade their consultants to provide their preferred hysterectomy. Our view is that that explicit attention to each of the three subcategories for each category in Table 4 provides a way out of such controversies.

\section{Shared model A3, B3, C3, D3}

Such an orientation means that information about treatment options and side effects flows both ways (A3) which requires mutual respect and collaborative communication. ${ }^{2}$ Participants $\mathrm{d} 1, \mathrm{~d} 2, \mathrm{n} 1, \mathrm{n} 2$, and $\mathrm{n} 6$ stated:

Doctors provide patients with oral information about the entire process, and information about surgical procedures, treatment options and consequences. Nurses give patients general information about the hospital stay, routines, and the preparations before surgery.

Doctor $\mathrm{d} 4$ stated:

I often sketch and explain treatment options to the patients, but the patients, of course, have to learn how they will predict the outcome of alternative treatment options, advantages and disadvantages.

Nurse $\mathrm{n} 2$ added:

In the consultation with cancer patients a nurse together with a doctor (on the doctor's request) jointly informed the patient, since patients often have questions and need follow up explanations and discussion to supplement the earlier provided information.

Healthcare professionals discuss treatment options (B3) with patients, which are evaluated in the context of the patients' needs. Patients inform healthcare professionals about their issues, preferences, lifestyle and knowledge about their illness and its treatment. Both healthcare professionals' and patients' knowledge are needed to manage illness successfully (C3). Patients receive abundant information which makes it important to simplify and make the information understandable for them.

Patient p7 stated:

I got the usual written information about the surgery, but it was just standardized letters. I also attended the usual preoperative visit with information. I was anxious before surgery and the doctors should have concretized the surgical treatment more systematically to me.

Patient $\mathrm{p} 7$ further stated that he found some of the written information contradictory. He had found amazingly much Internet information. Earlier he had asked for a second opinion for his back-pain and hunched position caused by Bechterew disease and was presented with recovery percentages varying greatly across hospitals, e.g. $100 \%$ chance of recovery in the US and a $50 \%$ chance in 0slo. Because of such uncertainty in all regards, including cost and time, he chose not to get surgery.

Healthcare professionals empower patients to understand the given information and find the best solution after which a decision is made jointly (D3). Doctor d3 stated:

I usually phrase myself in such way, that patients choose the treatment-alternative that I believe is best for them.

The reason for doctor d3's framing in this manner is that he experiences that the older blood vessels/thorax patients he operates either prefer to withdraw from decision making or are too weak to survive the operation.

Patients p5 and p6 stated that they would first and foremost lean on the doctors' recommendation, as also suggested by Kaplan. ${ }^{31}$ Similarly, Elwyn et al. ${ }^{32}$ stressed the importance of portraying options before checking whether the patients wish to be actively involved in the decision. Asking patients about their preferred level of involvement before they have become aware of the possible choices they face is to prejudge the interaction. If choices are difficult and the issues are painful, many patients will wish to withdraw from the decision-making process. In others, they will wish to make active contribution (p. 896).

\section{Informed model: A2, B2, C1, D1}

The healthcare professionals give accurate information to the patient (A2) based on the research evidence about the patients' disease and treatment options, ${ }^{7}$ and formulate options (B2). Thereafter patients integrate information (C1) and make decisions (D1).

This is in accordance with our data where doctors $\mathrm{d} 1, \mathrm{~d} 2, \mathrm{~d} 4$ stated that they give the patients accurate information about the actual procedures according to surgical treatment and anaesthesia. The two youngest doctors, $\mathrm{d} 1$ and $\mathrm{d} 2$, expressed that patients should talk with the doctor before surgery about the diagnosis and treatment alternatives and that the nurses, in technical cooperation with the doctors, should make written information about surgical treatment in the form of pamphlets available to patients. Doctor $\mathrm{d} 2$ stated that the nurses can support the patients in participating in decision-making processes in follow-up conversations. This requires the nurses to have good insight into what the doctor said and can convey this to the patient. Doctor $\mathrm{d} 2$ also proposed providing information about surgical treatment to the patients in the form of boxes of facts intended to be easily comprehensible by the patients, and designed to aid patients choose wisely among options and ensure that they understand important information about their treatment. Doctor $\mathrm{d} 4$ expressed that he prefers patients to take part actively in decision-making processes and share responsibility for which treatment options are chosen. Patient p4 suggested the availability of written information about present problems which patients could discuss with their families, to dampen elements of surprise which may arise during the consultation when discussing treat- ment options and consequences of treatment. The treatment method can differ for the same diagnosis and the same symptom, and multiple treatment options and surgical techniques can be used. She stated:

I want to choose as much as I can choose as a patient, but I don't want to make choices where I don't understand the consequences or do not have enough knowledge. It was important to be allowed to discuss what was going to happen, to get good information, so that I could ask the questions I needed answered.

In the informed model patients are thus accorded a more active role in both defining the problem (C1) for which they want help and in determining appropriate treatment (D1) ${ }^{33}$

Illustrating these subcategories further with literature findings, Charles et al. ${ }^{3}$ wrote that the patient is given information (A2) and left to make the decision (D1). Kaplan and Frosch ${ }^{34}$ wrote that the doctor merely provides the patient with information $<A 2>$, leaving clinical decisions solely in the hand of the patient $<$ D1> (p 542). Ling et al. ${ }^{35}$ stressed the means for facilitating patient participation in decision-making <which> includes: i) providing relevant information about the clinical situation, alternatives, and risks and benefits; ii) assessing the patient's understanding; and 3) giving the patient a clear opportunity to voice a preference ( $\mathrm{p} 23$ ). Further, Berry et al..$^{36}$ interviewed 44 men with localized prostate cancer and found that the patients wanted to hear the clinician's recommendation but also to be allowed to make major choices about treatment (D1). Important findings were that personal factors to the conversation along with medical factors turned out well and could guide the patient to making a good choice for treatment (D1). One example of the informed model is an amyotrophic lateral sclerosis patient who first receives information from the doctor (A2) and thereafter gives instructions not to perform tracheotomy or ventilation treatment before he gets terminally ill (D1), or to perform such treatment when he gets terminally ill (D1).

\section{Non-paternalistic model: A1 (alt.A3), B1, C1, D1}

As general knowledge and wealth increase in the population, and values associated with autonomy gets increased emphasis, patients may increasingly claim decision rights for their own body. A hypothetical example not found in the data is a wealthy patient who hires a team of health professionals or a research institute to investigate her illness, formulates options and instructs the institute how to operate (B1), requires information in return (alt.A3), integrates information herself (C1), and makes all decisions herself (D1). The patient choosing this approach is domineering in the sense of refusing to acknowl- 
edge information uncritically from healthcare professionals. The patient prefers to make medical decisions by herself and to have the healthcare professionals follow her decisions. This means viewing patients as principals and healthcare professionals as agents. As in principal-agent theory ${ }^{4,5}$ patients delegate the responsibility for providing treatment to healthcare professionals. The four doctors stated that they explain the actual treatment options and their competence on the actual surgical techniques, and that the nurses can have a follow-up conversation with the patients after the consultation. In substance, with various formulations, the four doctors pointed out that they had the time necessary to give patients the information they needed to ensure user involvement regarding surgical treatment, and they facilitated the patients with knowledge so that they could make their decisions about the surgical treatment.

Patient $\mathrm{p} 4$ stated that she wanted to have adequate information about surgery and treatment options based on best practice. She preferred to be prepared for the consultation so she could ask the relevant questions. She wanted to get the opportunity to influence the situation by choosing between one or more options, and further:

As a patient, I want written information or addresses on the Internet where I can find information on my own, about the surgical treatment. I often use the Internet to find information. I took the initiative to ask about removing healthy tissue from my pelvis to avoid cancer, since it could be hereditary in my family.

\section{Discussion}

\section{The participants' model preferences}

Tables 1 and 2 show the 18 participants' model preferences. Doctor $\mathrm{d} 4 \mathrm{\text {expressedthe }}$ highest preference for patient participation. He preferred the informed model since he operates orthopedic patients where surgical techniques are more mechanical and more easily explained to the patients. The two young doctors $\mathrm{d} 1$ and $\mathrm{d} 2$ expressed the second highest preference, among the doctors, for patient participation, also preferring the informed model, but parenthetically expressing some views consistent with the shared model. Their young age and recent education incorporating recent laws accounting for patient participation may have influenced them to be less paternalistic. In contrast, doctor $\mathrm{d} 3$ had the least preference, among the doctors, for patient participation, preferring the shared model. This may be due to him operating older complicated patients where the doctor is more influential. The high preference for patient participation among the doctors compared with nurses may be due to the doctors meeting an increasingly educated population not accepting paternalism. This stands in contrast to nurses providing patients with general information which to a lower degree requires taking a stand on paternalism.

The seven female nurses expressed a lower preference for patient participation, three preferring the shared model and four preferring the paternalistic model. This lower preference may be due to different experiences and interpretations of patient participation. One possibility is that nurses, through education and training, have been influenced by paternalism and continue to be loyal towards paternalism also after paternalism has lost some of its popularity. Many developments in hospitals are led by doctors who may capture societal trends, and apply these, before the nurses. In contrast, nurses may follow routines to a larger degree.

The four female patients' preferences were between those of the doctors and nurses. One preferred the informed model, two preferred the shared model, and one preferred the paternalistic model. The three male patients expressed the lowest preference for patient participation. One preferred the shared model, and two preferred the paternalistic model. Summing up, doctors were more positive towards patient participation than nurses, female patients were more positive than nurses who are more positive than male patients, and healthcare professionals as a group were more positive than patients.

The fact that the doctors scored higher than the nurses on patient participation contradicted the earlier findings by Spangler ${ }^{37}$ and Shepherd et al..$^{38}$ Spangler ${ }^{37}$ found that doctors were often reluctant to involve patients in decisions because of pessimism about the patients' ability to be active, and concern that doing so might take more of the doctors' time. This caused the doctors to be reluctant to involve patients in decision-making processes. Somewhat differently, we found that the nurses distinguished between information provided to patients by nurses and doctors, and that the information received was insufficient for a full understanding. Doctors gave patients more specific information about surgical procedures and treatment options than the nurses did. The nurses found that patients often had unanswered questions after their consultations with the doctors. Such lack of information might be unknown to the doctors, but visible to the nurses and might explain the differences on the scores between the doctors and nurses. Patients often did not have enough time to ask the doctor questions, or the doctor might not facilitate a situation where the patient could ask questions. Accordingly,
Shepherd et al. ${ }^{38}$ found that insufficient information at the first consultation and lack of time was the common barriers to shared decision-making in treatment by Australian cancer doctors. The doctors with less experience more frequently reported organizational and system issues as difficult. Educational trends and regulation of patient participation by law in Norway might cause freshly graduated healthcare professionals to be more positive toward patient participation. Healthcare professionals' roles could be impacted by legislation dictating patients to influence their own treatment (National Directorate for Health and Social Affairs, Norway, 2005). Influenced by these laws, healthcare professionals with long work experience might feel less threatened by the knowledge and power transfers from themselves to patients.

\section{Some characterizations of the results}

The importance of the role of information was underscored by the nurses in this study who experienced that after the patients' consultation with the doctors the patients often had many unanswered questions, which they posed to the nurses. It seems that patients had too little time for asking questions to the doctor, or the doctor might not have provided room for asking questions.

Although Table 2 shows that more male patients preferred the paternalistic model, and more female patients preferred the shared model, seven patients were too few to conclude about gender differences. The gender preferences are reversed for the seven female nurses, four of whom preferred the paternalistic model. We could not detect that anything in the female doctor's preference was gender based.

Each participant was interviewed separately. This gave each interviewee the opportunity to express views and feelings freely, without being constrained by the presence of other interviewees. Proceeding through 18 interviewees separately allowed for illuminating a multiplicity of types of interaction and communication through the four categories.

\section{Methodological considerations}

In qualitative studies, the researcher is the main data-gathering and analytical instrument. Interaction between the interviewer and the interviewee could influence the creation of meaning. ${ }^{19}$ The trustworthiness of the findings was enhanced by describing the clinical setting, sampling method and the interview situation. To reduce subjectivity in the analysis several researchers and experts were involved, representing different professions and cultural backgrounds. We believe to have succeeded capturing the nuances in the data while translating into English. 


\section{Facts and values in the four categories}

Much discussed in philosophy of science is the fact/value distinction. See Putnam ${ }^{39}$ for a critical view, and the references therein. In our view the first two categories involve facts to a larger degree than values, and vice versa for the last two categories. That is, the first two categories are less value laden than the last two categories. A first step in many processes is the gathering and dissemination of information. That process can be mechanical focusing on facts. Once information is compiled and disseminated, the next step is to formulate options, which initially can be done creatively and uncritically, by generating a formal list based on facts. When information is disseminated and options are formulated, the participants seek to limit the extent to which values are present or imposed. The participants may strive to reach value neutrality, but we cannot expect them to obtain it. ${ }^{40}$ In contrast, the last two categories are explicitly value laden since values play a role when information is integrated and control is initiated. Information integration can be made objectively or subjectively according to the actors' values, which include their beliefs and preferences. The last category pertains to control which means rejection versus acceptance of paternalism, empowering patients in decision-making processes, and choosing options. Essential is whether healthcare professionals, patients, or both, decide which surgical treatment to undertake, which involves values.

\section{Ideological and political factors}

The space spanned by the 81 models can be assessed ideologically and politically according to criteria. That is, whether the first or second or third subcategory is chosen for each of the four categories reveals the manner in which patients, healthcare professionals, or both, are involved in each category. For example, if the second subcategory, where healthcare professionals are especially active in the specified senses, is chosen for all the four categories, then we know that we tend towards the paternalistic model. Conversely, we tend towards the non-paternalistic model if the first subcategory is chosen for each category. Analyzing the 81 combinations thoroughly reveals insights into issues such as differences between doctors, nurses and patients with respect to power, information, competence, ability, and needs, capacity and willingness to provide, request, and require services, egalitarianism, non-egalitarianism, paternalism, and non-paternalism in patient participation. Practice for a healthcare provider concerned about patient participation can be assessed empirically to determine how it fits into the theoretical structure of 81 models. Strategies can be implemented to move practice from one part of the theoretical structure, e.g. where patient participation plays a minor role in specified sense, to another part where patient participation plays a more prominent role.

\section{Study's limitations and strengths}

First, the sample of 18 participants affects generalizability. ${ }^{16-18}$ Such a relatively small sample allowed for in-depth interviews of each participant, which may have brought to the surface views, which may not have been obtainable through more superficial investigation. Some views were expressed by many participants and other views by fewer. One should be careful claiming that all views in the data would be equally representative in a larger sample with broader demographic characteristics. Second, selecting participants for interviews using purposive sampling is not as robust as random sampling. However, purposive sampling ensured that the participants met the criteria of diverse background described above in the subsection Clinical setting and sample. Thus, we believe that the representativeness of the views is reasonably good.

Societal trends, for example from more overt paternalism one century ago to less paternalism today, may hypothetically have induced the participants to report too positive attitudes toward patient participation. However, we believe the experienced interviewer has accounted for this hypothesis and gathered a reasonably unbiased account through each interview.

The interviews for this study were conducted with professionals and patients separately, and it might be difficult to provide solid evidence to show how values are present in the manner healthcare professionals and patients operated across subcategories and categories. For example, it can be argued that even if a doctor is sharing information and discussion treatment options with a patient, his/her own beliefs and values about which treatment would be optimal is likely to be part of this process. Patient $\mathrm{p} 3$ was the only patient interviewed before her operation, and the only patient with no earlier operations. Her answers were shorter than those of the other patients, possibly because of uncertainty. Whether this somehow confounded the results is hard to assess.

The issue of whether interviewing 18 participants is sufficient to suggest a generalized theoretical structure of 81 models can first be addressed by observing that research operates in both the domains of empirical discovery and theoretical justification. Although empirical discovery is the common domain in which to start, one can in principle start in any domain.
The current study started in the domain of empirical discovery by interviewing 18 participants, and has thereafter proceeded between the two domains.

\section{Relevance to clinical practice}

The results show that the healthcare professionals were responsible to meet the patients' needs for information in a sensible way so the information is meaningful to the patients. Healthcare professionals and patients have to exchange information to achieve patient participation. A better educated and informed public exercises its right to choose treatments, procedures, and providers and raises questions about the quality of health services being provided. ${ }^{41}$ This involves more dynamic dialogue and collaboration between healthcare professionals and patients. Asking questions, obtaining information, choosing from different alternatives together with enough time for patients, promote patients' participation in decision-making processes. Enough time for conversation and the patients' possibilities for further talk if necessary are essential when empowering patients in treatment decisions. Nurses bedside the patients can support the patients in decision-making processes. The nurses, in technical cooperation with the doctors, may work out written information about surgical treatment designed for patients. This may help healthcare professionals and patients, in the variety of ways specified in this paper, to disseminate information, formulate options, integrate information, and control appropriately.

\section{Future research}

Future research should explore which of the 81 models expresses the most suitable organization to regulate patient participation. Such suitability may depend on the organization objectives. Further steps are to distinguish between the different kinds of information flowing between healthcare professionals and patients, quantify the information flows, scrutinize how options are formulated differently across different subject areas, investigate how information is integrated when abundant versus scarce, across different subject areas, and how control operates in various situations.

Patients' attitudes may be influenced by the kind of surgery. For example, a man admitted for prostate cancer may die if not undergoing surgery, while a woman refusing breast implants may suffer no harmful side effects. Future research may address how patients' attitudes vary across kinds of surgeries, with associated options and consequences, and related to laws, regulations and management philosophies. Although we interviewed surgical patients, we believe the three subcategories for each of the four categories apply generally for patient participation across 
healthcare. It would be beneficial to verify the results across a larger population of different kinds of patients, applying multiple methods of investigation, and analyzing in more detail preferences for the 81 models. It would also be interesting to analyze the relationships between respondents' preferences for the 81 models (including preferences for participation in decision-making processes), and the impact of these preferences on actual behavior. Variables that could be explored are patients' self-efficacy, coping styles and patients' preferences for participating in treatment processes.

In the study two patients were interviewed before surgery, and five patients were interviewed after surgery. Future research may additionally interview patients not undergoing surgery, before and after treatment. Furthermore, interviews can be conducted jointly with healthcare professionals and patients, in smaller or larger subgroups.

\section{Conclusions}

The aims and objectives of this study were to clarify patient participation by developing a systematic structure of $3^{4}=81$ models spanned out by three subcategories for each of four categories. Earlier attempts have lacked specificity. Choosing a qualitative research design and applying purposive sampling, four doctors, seven nurses, and seven patients were interviewed. The preferences of these were mapped onto the theoretical structure. Applying content analysis, meaning units were identified, condensed and coded. The four well-known paternalistic, shared, informed, and non-paternalistic models were positioned within the structure. We developed four categories, i.e. information dissemination, formulation of options, integration of information and control. These are exhaustive, and mutually exclusive through time causing a top-down process where one occurs before the other through four stages. The three subcategories specify how patients, healthcare professionals, or both, operate within each category. Our conclusions are that delineating a structure of $3^{4}=81$ models, based on four categories and three subcategories, gives a richer structure than what has earlier been available. This almost all-embracing structure enables pinpointing the exact nature of any culture involved in care of patients, which illuminates how the culture reflects or can potentially be altered to reflect values of patient care that we respect. The paper illustrates how clinical practice is assessed empirically to determine its match with the structure. Strategies can be implemented to move practice from one part of the structure to another part.

\section{References}

1. Parsons T. The social system. London: Routledge and Kegan Paul; 1951.

2. Charles C, Whelan T. Shared decisionmaking in the medical encounter: what does it mean? (or it takes at least two to tango). Social Sci Med1997;44:681-92.

3. Charles C, Gafni A, Whelan T. Decisionmaking in the physician-patient encounter: revisiting the shared treatment decision-making model. Social Sci Med 1999;49:651-61.

4. Arrow KJ. Uncertainty and the welfare of economics of medical care. Bull World Health Organ 2004;82:141-9.

5. Scott A, Vick S. Patients, doctors and contracts: an application of principal-agent theory to the doctor-patient relationship. Scottish J Pol Econ 1999;46:111-34.

6. Daykin N, Sanidas M, Tritter J, et al. Developing user involvement in a UK cancer network: professionals' and users' perspectives. Critical Public Health 2004;14: 277-94.

7. Charles C, Whelan T, Gafni A. What do we mean by partnership in making decisions about treatment? Br Med J 1999;319:780-2.

8. Cahill J. Patient participation: a concept analysis. J Adv Nurs 1996;24:561-71.

9. Charles C, Gafni A, Whelan T, O'Brien MA. Cultural influences on the physicianpatient encounter: the case of shared treatment decision-making. Patient Educ Counsel 2006;63:262-7.

10. Taylor TR. Understanding the choices that patients make. J Am Board Family Pract 2000;13:124-33.

11. Mulley AG Jr. Developing skills for evidence-based surgery: ensuring that patients make informed decisions. Surg Clin North Am 2006;86:181-92.

12. Coulter A. Paternalism or partnership? Br Med J 1999;319:719-21.

13. Gaston CM, Mitchell G. Information giving and decision-making in patients with advanced cancer: a systematic review. Social Sci Med 2005;61:2252-64.

14. Moumjid N, Carrère MO, Charavel M, Brèmond A. Clinical issues in shared decision-making applied to breast cancer. Health Expect 2003;6:222-7.

15. Petersson LM, Nordin K, Glimelius B, et al. Differential effects of cancer rehabilitation depending on diagnosis and patients' cognitive coping style. Psychosom Med 2002;64:971-80.

16. Polit DF, Beck CT. Nursing research, 8th ed. Philadelphia, PA: Lippincott Williams and Wilkins; 2008.

17. Blaikie N. Designing social research. Cambridge: Polity Press; 2005.

18. Patton MQ. Qualitative research and eval- uation methods, 3rd ed. Thousand Oaks, CA: Sage Publications; 2002.

19. Graneheim UH, Lundman B. Qualitative content analysis in nursing research: concepts, procedures and measures to achieve trustworthiness. Nurse Educ Today 2004;24: 105-12.

20. Granerud A, Severinsson E. Knowledge about social networks and integration: a co-operative research project. J Adv Nurs 2007;58:348-57.

21. Høye S, Severinsson E. Intensive care nurses' encounters with multicultural families in Norway: an exploratory study. Intens Crit Care Nurs 2008;24:338-48.

22. Nystedt A, Högberg U, Lundman B. Women's experiences of becoming a mother after prolonged labour. J Adv Nurs 2008;63:250-8.

23. Hök J, Tishelman C, Ploner A, et al. Mapping patterns of complementary and alternative medicine use in cancer: an explorative cross-sectional study of individuals with reported positive "exceptional" experiences. BMC Complement Altern Med 2008;8:48.

24. Gustafsson B, Ponzer S, Heikkil K, Ekman S. The lived body and the perioperative period in replacement surgery: older people's experiences. J Adv Nurs 2007;60:20-8.

25. Morse J. Confusing categories and themes. Qual Health Res 2008;18:727-8.

26. Churchill GA jr. A paradigm for developing better measures of marketing constructs. J Market Res 1979;16:64-73.

27. Imle MA, Atwood JR. Retaining qualitative validity while gaining quantitative reliability and validity: development of the transition to parenthood concerns scale. Adv Nurs Sci 1988;11:61-75.

28. Coulter A. Partnerships with patients: the pros and cons of shared clinical decisionmaking. J Health Serv Res Policy 1997;2: 112-21.

29. Kennedy I. Patients are experts in their own field. Br Med J 2003;326:1276.

30. Entwistle VA, Skea ZC, O'Donnell MT. Decisions about treatment: interpretations of two measures of control by women having a hysterectomy. Social Sci Med 2001;53:721-32.

31. Kaplan RM. Shared medical decision making. A new tool for preventive medicine. Am J Prevent Med 2004;26:81-3.

32. Elwyn G, Edwards A, Kinnersley P, Grol R. Shared decision making and the concept of equipoise: the competences of involving patients in healthcare choices. Br J Gen Pract 2000;50:892-9.

33. Braddock CH, Edwards KA, Hasenberg NM, et al. Informed decision making in outpatient practice. J Am Med Assoc 1999;282: 2313-20.

34. Kaplan RM, Frosch DL. Decision-making 
in medicine and health care. Annu Rev Clin Psychol 2005;1:525-56.

35. Ling BS, Trauth JM, Fine MJ, et al. Informed decision-making and colorectal cancer screening: is it occurring in primary care? Med Care 2008;46:23-9.

36. Berry D, Ellis WJ, Woods NF, et al. Treatment decision-making by men with localized prostate cancer: the influence of personal factors. Urol Oncol
2003;21:93-100.

37. Spangler N. Member behaviour change. In: Kongstvedt P, ed. The managed care handbook, $4^{\text {th }}$ ed. Gaithersburg, MD: Aspen Publisers, Inc; 2001. Chapter 34.

38. Shepherd HL, Tattersall MNH, Butow PN. Physician-identified factors affecting patient participation in reaching treatment decisions. J Clin Oncol 2007;26:1724-31.

39. Putnam H. The collapse of the fact/value dichotomy and other essays. Cambridge: Harvard University Press; 2002.

40. Tribe LH. Policy science: analysis or ideology?. Philos Public Affairs 1972;2:66-110.

41. Gallant MH, Beaulieu MC, Carnevale FA. Partnership: an analysis of the concept within the nurse-client relationship. J Adv Nurs 2002;149-57. 